Int. J. Dev. Biol. 55: 953-960

doi: $10.1387 / \mathrm{ijdb} .113348 \mathrm{yz}$

\title{
Multiple effects of the cellular prion protein on tooth development
}

\author{
YAN ZHANG ${ }^{1, \#, ~ S E O N G-O H ~ K I M ~}{ }^{1,2, \#, ~ S I B Y L L E ~ O P S A H L-V I T A L ~}{ }^{1,3,}$ SUNITA P. HO ${ }^{4}$, \\ JEAN-BAPTISTE SOURON ${ }^{3}$, CHARLES KIM ${ }^{1}$, KURT GILES ${ }^{5,6}$ and PAMELA K. DEN BESTEN ${ }^{*, 1}$ \\ ${ }^{1}$ Department of Orofacial Sciences, University of California San Francisco, USA, ${ }^{2}$ Department of Pediatric Dentistry, \\ Oral Science Research Center, College of Dentistry, Yonsei University, Seoul, Korea, ${ }^{3}$ University Paris Descartes, \\ EA2496, AP-HP, France, ${ }^{4}$ Division of Biomaterials and Bioengineering, Department of Preventive and Restorative \\ Dental Sciences, ${ }^{5}$ Institute for Neurodegenerative Diseases and ${ }^{6}$ Department of Neurology, \\ University of California San Francisco, USA.
}

\begin{abstract}
The role of the prion protein (PrP) in transmissible spongiform encephalopathies has been the focus of intense investigation. However, less is known about the physiological function of normal cellular $\operatorname{PrP}\left(\mathrm{PrPC}^{\mathrm{C}}\right)$. In adult human teeth, $\mathrm{PrP}^{\mathrm{C}}$ has been identified in odontoblasts, cementoblasts and epithelial remnants of Malassez. In this study, we have localized $\operatorname{PrP}^{\mathrm{C}}$ in developing human and mouse teeth, and investigated the function of PrP using a PrP-knockout $\left(P_{r n p} p^{0 / 0}\right)$ mouse model. PrPc was detected in developing human and mouse ameloblasts and odontoblasts. In vitro, undifferentiated dental mesenchymal cells from embryonic day 18 (E18) Prnp ${ }^{0 / 0}$ mouse molars proliferated much more rapidly compared to age-matched, wild-type (wt) mouse molar dental mesenchymal cells. Histochemistry and immunohistochemical analyses showed a subtle but measurable phenotype, with the absence of PrP resulting in earlier initiation of both dentin and enamel formation. Consistent with this finding, laser microdissected odontoblasts from newborn Prnpo/0 mouse incisors had a reduced proliferation rate, as measured by the expression of proliferating cell nuclear antigen (PCNA), and increased type 1 collagen mRNA expression. Dentin microhardness of the fully erupted molars was reduced and incisal enamel mineralization was delayed in Prnpo/0 compared to age-matched wt mouse teeth. Taken together, these results suggest that $\mathrm{PrP}^{\mathrm{C}}$ affects multiple processes involved in tooth formation, through regulating the differentiation of ameloblasts and odontoblasts.
\end{abstract}

KEY WORDS: tooth development, prion protein, ameloblast, odontoblast

\section{Introduction}

The prion protein (PrP) is a glycophosphatidylinositol-anchored glycoprotein. It is highly conserved among mammals and is also present in birds, reptiles and amphibians (Premzl and Gamulin 2007), suggesting an important functional role. Normal cellular PrP, termed $\mathrm{PrP}^{\mathrm{C}}$, is widely expressed in adult tissues, predominantly in neuronal cells, and its expression is regulated both embryonically (Manson et al., 1992, Tremblay et al., 2007) and postnatally (Lazarini et al., 1991, McKinley et al., 1987). However, mice in which PrP expression has been genetically abrogated are not only viable, but appear to have only subtle phenotypes (Bueler et al., 1992, Manson et al., 1994a).

Expression of $\mathrm{PrP}^{\mathrm{C}}$ was detected in inner and outer epithelial layers of the E16.5 mouse tooth primordium by in situ hybridization
(Manson et al., 1992), and in the dental papilla and ameloblasts of E18.5 mice by immunohistochemistry (Khan et al., 2010). PrPc was also detected in odontoblasts, cementoblasts and epithelial remnants of Malassez in adult human dental tissues by immunohistochemistry (Schneider et al., 2007). These cells are all involved in the formation of mineralization tissues. In mice infected with the Me7 prion strain, the pathological isoform of the prion protein, $\mathrm{PrP}^{\mathrm{Sc}}$, was observed in the rests of Malassez lining the tooth surface (Okada et al., 2010).

Teeth form through sequential reciprocal signaling interactions between ectodermal-derived dental epithelial cells and cranial neurocrest differentiated mesenchymal cells (Sharpe 2001, Thesleff

Abbreviations used in this paper: DMC, dental mesenchymal cell; PCNA, proliferating cell nuclear antigen; $\operatorname{Pr}$, prion protein; $\operatorname{PrP}^{\mathrm{C}}$, normal cellular prion protein.

\footnotetext{
*Address correspondence to: Pamela DenBesten. 513 Parnassus Ave, San Francisco, CA 94143-0422, USA. Tel: +1-415-502-6383. Fax: +1-415-476-4204. e-mail: pamela.denbesten@ucsf.edu \# Note These authors contributed equally to this work.
} 
A
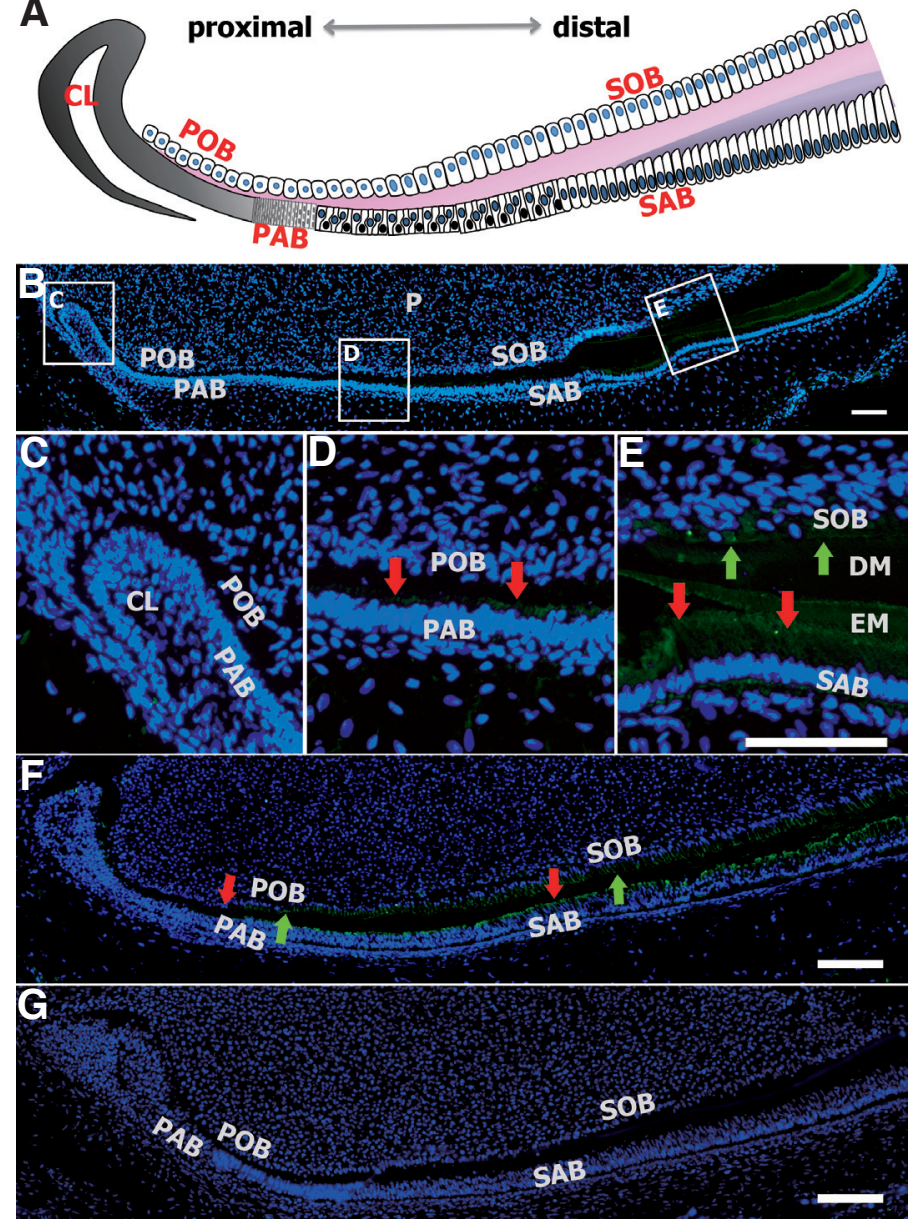

and Nieminen 1996). Tooth formation initiates as the oral epithelial cells, lining upper and lower jaws in the first arch at the presumptive tooth sites, proliferate and thicken to form primary epithelial bands (also named dental placode). Proliferating epithelial cells invaginate into the underlying dental mesenchyme. In response to signals from the dental epithelium, the dental mesenchyme condenses and forms a bud structure (Bei and Maas 1998, Mandler and Neubuser 2001, Neubuser et al., 1997). The epithelium then forms a cap-like structure overlying the dental mesenchyme.

Individual tissues in the tooth continue to differentiate during the subsequent bell stage (mouse E16 to postnatal days). As cusp morphogenesis continues, cytodifferentiation begins and mesenchymal cells lining the dental papilla differentiate into
Fig. 1. Immunohistochemical staining of PrP in human fetal (B-E) and mouse (F,G) tooth organs. (A) The diagram illustrates the dynamic development of dental mesenchymal cells and dental epithelial cells during incisor morphogenesis. The dental mesenchymal cells adjacent to epithelial cells develop into polarized pre-odontoblasts (POBs) first, then continuously develop into secretory odontoblasts (SOBS), which secret dentin matrix and are responsible for the dentin formation. The dental epithelial precur sor cells located in the cervical loop (CL) migrate to the basal layer around the outside of the loop. The basal epithelial cells polarize and elongate to become pre-ameloblasts (PABs), then differentiate into secretory ameloblasts (SABs), which secrete enamel matrix proteins and attract minerals to initiate enamel biomineralization. (B) Staining of human developing incisor tooth organ showed significant upregulation of PrP (green staining) as the cells entered the secretory stage. (C) Higher magnification of the cervical loop (CL) area showed no PrP signal was detected. (D) Gradually increased PrP staining was detected first in pre-ameloblasts (PAB; red arrows). (E) PrP signal was observed in the fully differentiated secretory ameloblasts (SAB; red arrows), and secretory odontoblasts (SOB; green arrows). (F) In the mouse incisor, immunopositive PrP signal first appeared in pre-odontoblasts (POB; green arrows). The signals became more intense as the cells differentiated into SOB (green arrows) and SAB (red arrows). (G) Prnp $\%$ mouse incisors were immunonegative for PrP. All the blue stain is the counterstaining of nuclei with Hoechst 33324. Bars $=100 \mu \mathrm{m}$, bar in $E$ applies to $C$ and D. Pre-odontoblasts (POB), pre-ameloblasts (PAB), secretory odontoblasts (SOB), secretory ameloblasts (SAB), dental pulp $(P)$, cervical loop $(C L)$, dentin matrix $(D M)$, enamel matrix (EM).

columnar odontoblasts. As long as the odontoblasts begin to secrete dentin matrix, the adjacent pre-ameloblasts differentiate into ameloblasts (Harada et al., 1999). Enamel mineralization begins as soon as secretory ameloblasts secrete amelogenins and other non-amelogenin proteins, all of which self-assemble to form a mineralizing enamel matrix on the dentin surface. At the transition between secretion and maturation stages, matrix proteins are rapidly removed by matrix proteinases leaving a porous enamel matrix. This matrix is subsequently completely mineralized as maturation stage ameloblasts modulate between smooth and ruffle bordered cells. At the end of enamel maturation, ameloblasts undergo apoptosis and finally disappear as the tooth erupts (Vaahtokari et al., 1996).

In this study, we first localized $\mathrm{PrP}^{\mathrm{C}}$ in human developing incisors and mouse teeth at various developmental stages, then further investigated the role of $\mathrm{PrP}^{\mathrm{c}}$ on tooth development by using mouse tooth models. Mouse molars are rooted teeth similar to human teeth, while mouse incisors are continuously growing, allowing studies of all stages of tooth formation in a single tooth. PrP-knockout (ko; Prnpo/0) mice and wild-type (wt) mice were used to investigate the physiological function of PrP in tooth development. Cell proliferation and differentiation was
A

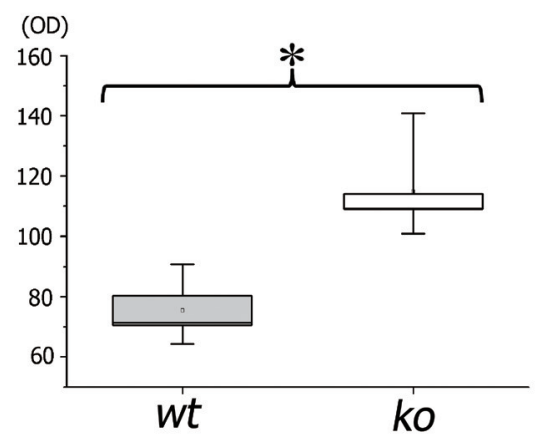

B

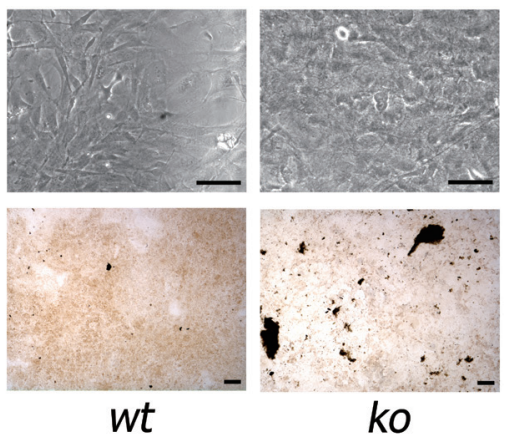

Fig. 2. The effect of PrP on undifferentiated dental mesenchymal cells (DMCs) isolated from E18 mouse molars. (A) $D M C s$ from Prnp $^{/ 0}(\mathrm{Ko})$ mice proliferated faster, as indicated by the significantly increased optical density $(O D)$ compared to cells isolated from wt mice ${ }^{*} p<0.05, n=4$; Student's $t$ test) based on the BrdU cell proliferation assay. (B) The top panels showed that DMCs from Prnp ${ }^{0 / 0}$ mice plated at the same density as wt cells, were more confluent after 5 days in culture (Bars $=10 \mu \mathrm{m})$. The lower panels showed von Kossa staining of DMCs grown for 2 wks in mineralizing media, and demonstrated the increased mineralization of DMCs isolated from Prnp ${ }^{0 / 0}$ compared to wt mice (Bars $=100 \mu \mathrm{m}$ ). Representative results from three independent experiments. 
compared in developing dental mesenchymal cells isolated from E18 wt and ko mice, as well as in differentiated pre-odontoblasts and secretory odontoblasts microdissected from newborn wt and ko mice. The progressive formation of dentin and enamel were investigated in newborn mouse incisors, and microhardness was measured in fully formed first mouse molars.

The results of this study showed that $\mathrm{PrP}^{\mathrm{C}}$ had the specific effects on different stages of tooth cell differentiation and matrix mineralization. The primary phenotypes in $\mathrm{Prnp}^{0 / 0}$ mice included enhanced pulp mesenchymal cell proliferation and mature dentin with a reduced hardness. Enamel mineralization was initiated

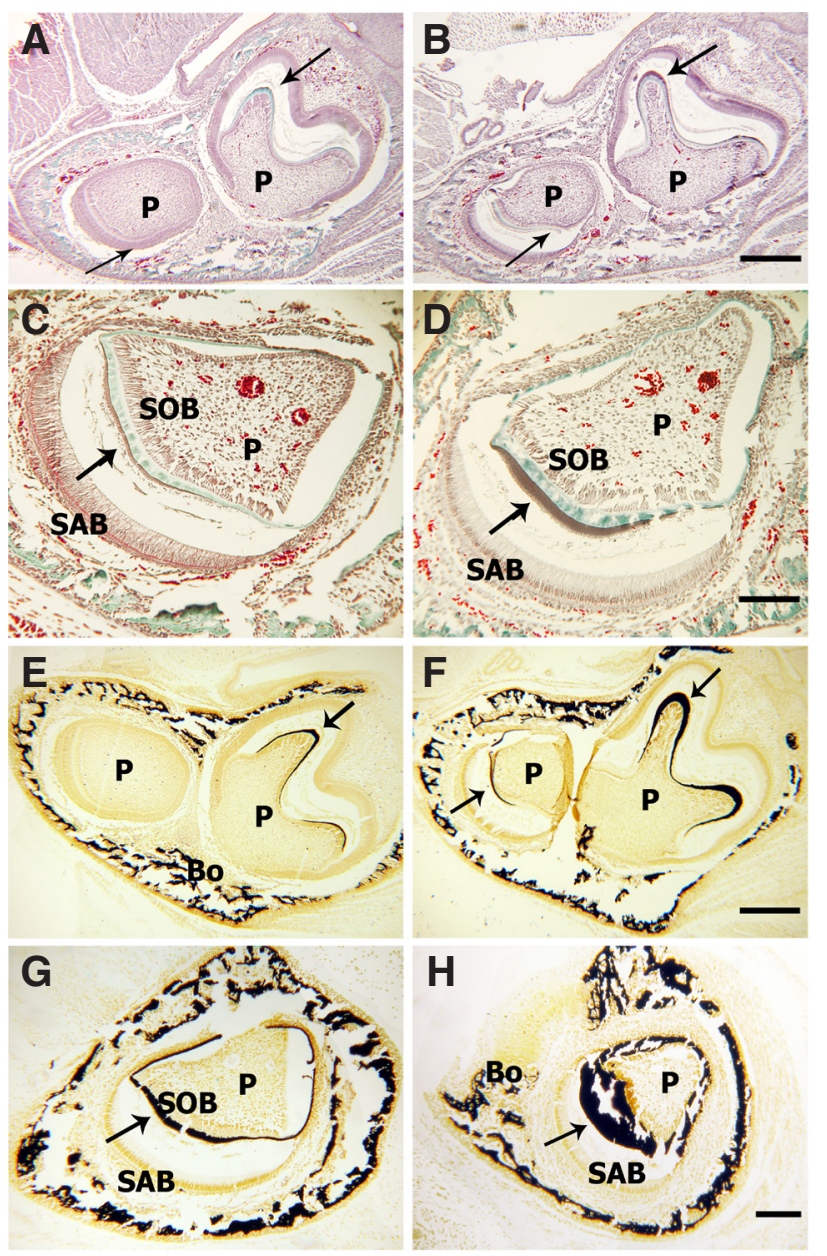

earlier, followed by a subsequent delay in final mineralization. These effects suggest that $\mathrm{PrP}^{\mathrm{c}}$ may be involved in mediating differentiation of the cells responsible for tooth hard tissue formation.

\section{Results}

\section{Prion protein (PrP) was localized in both odontoblasts and ameloblasts of developing teeth}

In developing human teeth, immunohistochemical analysis showed PrPC localized at the apical border of pre-ameloblasts and secretory ameloblasts, but not apparent in the developing dental mesenchyme until the secretory stage of dentin formation (Fig. 1 B-E). In the continuously growing mouse incisor, positive $\mathrm{PrP}^{\mathrm{C}}$ immunostaining was first detected in pre-odontoblasts, and became more intense as the cells differentiated to secretory stage (Fig. 1F). The positive immunostaining signal was also detected
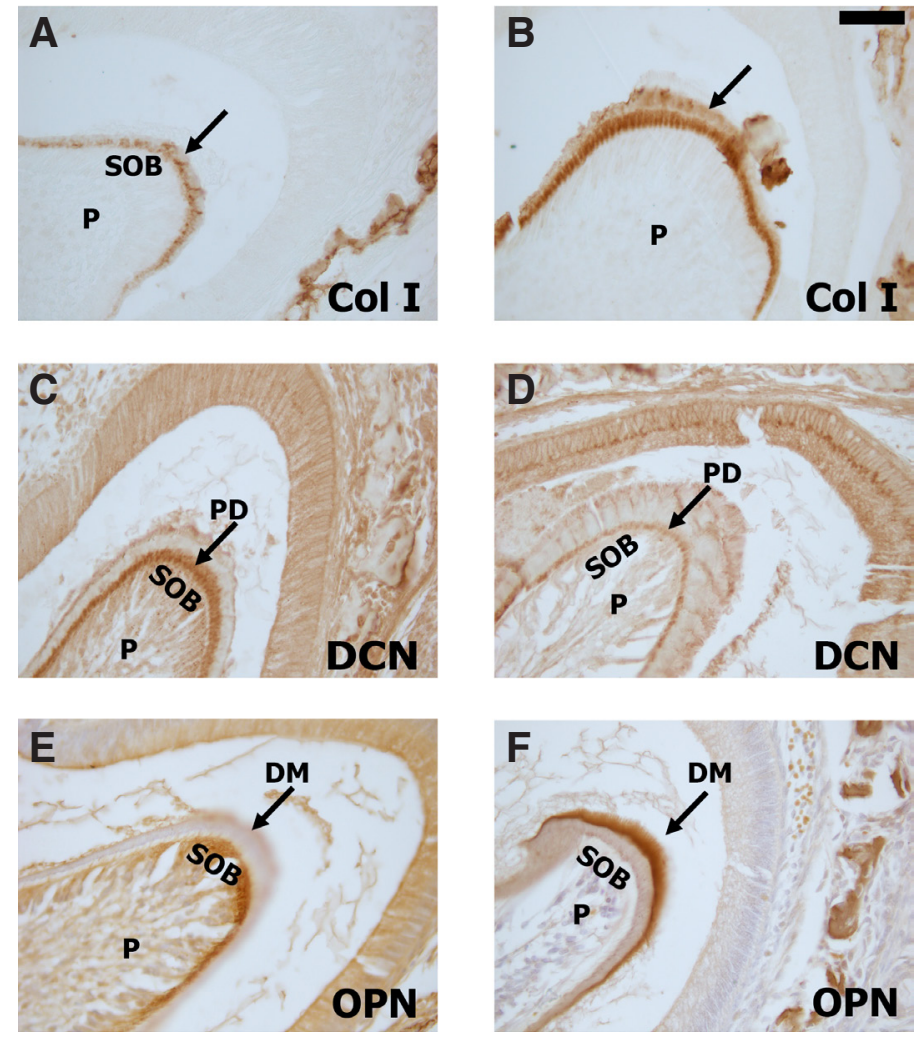

Fig. 3 (Left). Histological comparisons of newborn wt (A,C,E,G) and Prnp ${ }^{0 / 0}$ (B,D,F,H) mouse mandibles. Newborn mouse mandibles were collected, fixed, embedded, and cut into $7 \mu \mathrm{m}$-thick transversal sections. Sections at the same distance from the incisal tip were examined and compared. H\&E staining of the wt mouse mandibles (A) showed dentin (green; indicated by arrow) but no enamel matrix formation was visible in molar, and no dentin or enamel formation was detected on the underlying cross section of the incisor (indicated by arrow). However, in the Prnp $\%$ mouse (B) enamel matrix had begun to form on the molar (red) and dentin matrix (green) had begun to form on the underlying incisor (indicated by arrows). Trichrome staining (C,D) showed a greater width of enamel (brown) and dentin (green) (indicated by arrows) in the Prnp ${ }^{\%}$ mice (D) as compared to wt mice (C). Correlated to this increase in the matrix secretion, von Kossa staining showed increased mineralization in the enamel and dentin matrices (indicated by arrows) of $\mathrm{Prnp}^{0 / 0}(\mathbf{F}, \mathbf{H})$ compared to wt mice $(\mathbf{E}, \mathbf{G})$. Bars: $B=500 \mu \mathrm{m}, \mathrm{D}=100 \mu \mathrm{m}, \mathrm{F}=500 \mu \mathrm{m}, \mathrm{H}=200 \mu \mathrm{m}$, and apply to panels $\mathrm{A}, \mathrm{C}, \mathrm{E}$ and $\mathrm{G}$ respectively. Secretory ameloblast (SAB), secretory odontoblast (SOB), bone (Bo) and dental pulp (P).

Fig. 4 (Right). Immunohistochemical staining of type I collagen (Col I), decorin (DCN) and osteopontin (OPN) in newborn wt (A,C,E) and Prnpo/0 (B,D,F) molars. Staining of Prnp $\% 10$ mouse molars showed increased type I collagen immunolabeling in odontoblasts and dentin matrix (B) (indicated by arrows) compared to wt molars (A). The predentin (PD) stained positive for decorin (C,D) (indicated by arrows), with decreased immunostaining in the Prnp $\%$ mouse molars (D). Anti-osteopontin antibody was localized in the dentin matrix (indicated by arrows), and was increased in the Prnp $/ 0$ mouse molar (E) compared to wt molar (F). Bar in B=100 um and applies to all panels. Secretory odontoblast (SOB), dental pulp (P), predentin (PD) and dentin matrix (DM). 

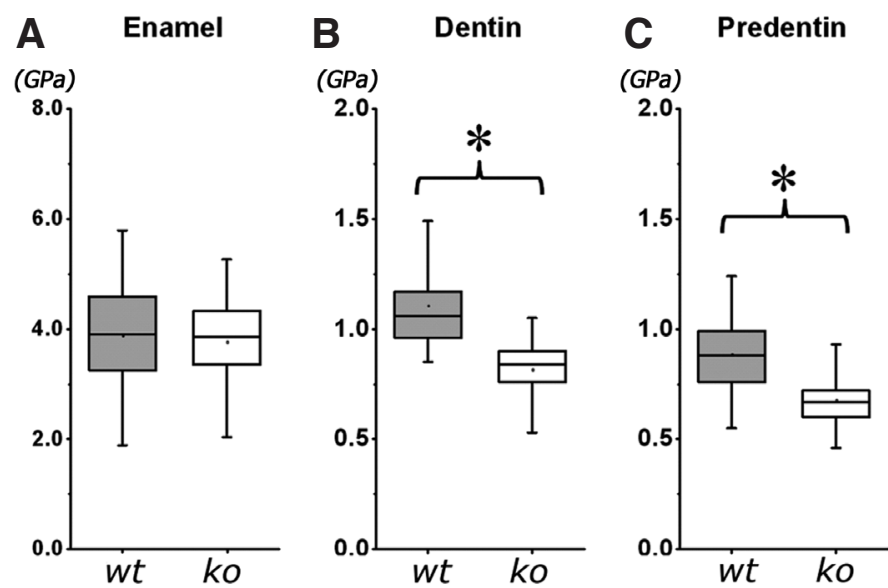

Fig. 5. Microhardness of enamel, dentin and predentin in adult mouse molars, determined by microindentation. Although there was no significant difference in enamel hardness (A), the dentin (B) and predentin (C) of Prnp ${ }^{0 / 0}(\mathrm{ko})$ mice had a significantly decreased hardness compared to wt mice ( ${ }^{*} p<0.05, n=6$; Student's t-test $)$.

in the secretory ameloblasts. There was no signal for $\mathrm{PrP}^{\mathrm{C}}$ in the Prnp ${ }^{0 / 0}$ mouse (Fig. 1G).

Dental mesenchymal cells isolated from E18 Prnp ${ }^{0 / 0}$ mouse molars had increased proliferation rate, leading to more rapid mineral formation in vitro

Analysis by BrdU immunoassay showed that embryonic dental mesenchymal cells derived from E18 Prnpo/0 mouse molars had enhanced proliferative activity compared to age-matched $w t$ control cells $(p<0.05, n=4)$ (Fig. $2 A)$. When the cells were grown

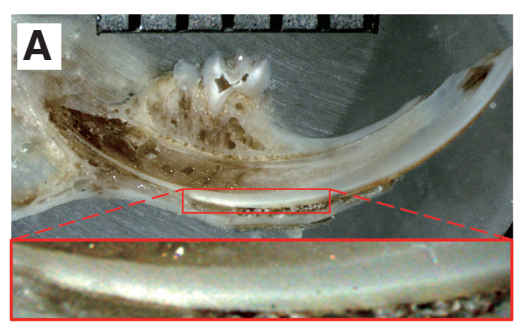

C

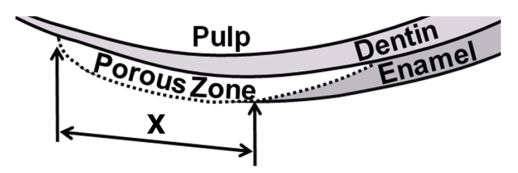

E

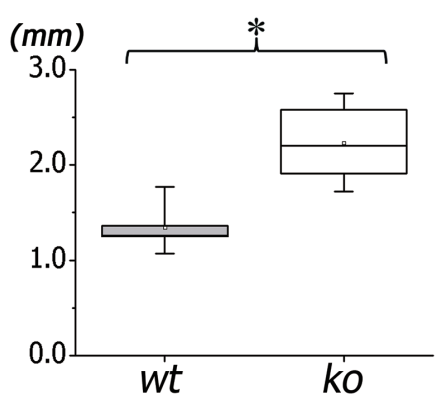

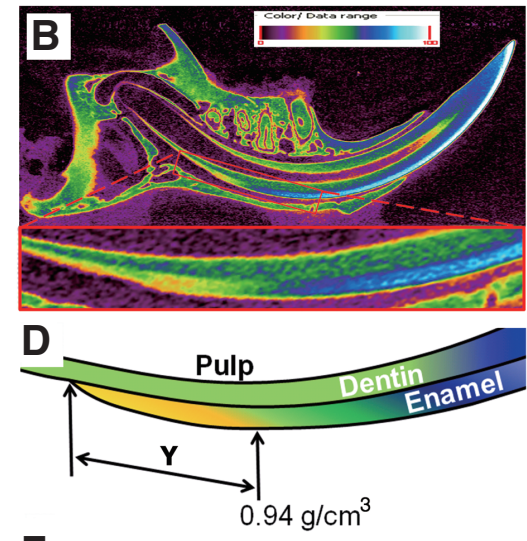

$\mathbf{F}$

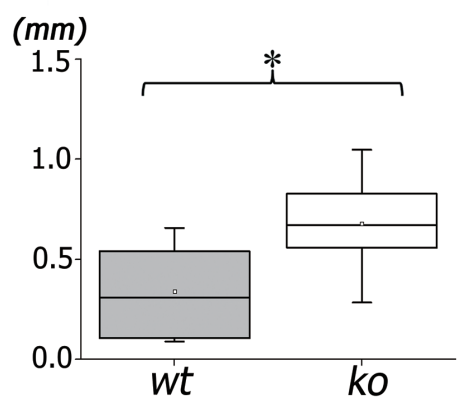

in mineralization media for 2 wks, the more rapidly proliferating cells isolated from $\mathrm{Prnp}^{0 / 0}$ mice, differentiated sooner and formed more mineralizing nodules as indicated by increased von Kossa staining (Fig. 2B).

\section{Early initiation of odontoblast and ameloblast cell differentia- tion and matrix apposition were detected in newborn Prnp ${ }^{0 / 0}$ mouse teeth}

Cross-sections of mouse mandibles, taken at the same distance from the incisal tips, showed earlier initiation of dentin and enamel formation in Prnp ${ }^{0 / 0}$ mice compared to the wt mice (Fig. $3 \mathrm{~A}, \mathrm{~B}$ ). Sections slightly more incisally located, at a later stage of matrix secretion, showed that the $P_{r n p}{ }^{0 / 0}$ mice had a relatively thicker enamel matrix (Fig. 3 C,D), and a more mineralized dentin matrix compared to $w t$ mice (Fig. $3 \mathrm{E}-\mathrm{H}$ ). These results were confirmed on three independent samples of $\mathrm{Prnp}^{0 / 0}$ and $w t$ mice.

Type I collagen immunostaining signal was increased in the Prnp $^{0 / 0}$ newborn mouse odontoblasts and dentin matrix (Fig. 4 $A, B)$. Immunostaining signals for decorin in predentin were reduced in the Prnp ${ }^{0 / 0}$ mouse teeth compared to wt (Fig. 4 C,D), whereas osteopontin was increased in the Prnpo//0 mouse dentin matrix (Fig. $4 \mathrm{E}, \mathrm{F})$. These results were confirmed in three sets of independent samples. qPCR analysis on laser microdissected pre-odontoblasts and secretory odontoblasts also showed enhanced differentiation of $\mathrm{Prnp}^{0 / 0}$ odontoblasts with a 27 fold reduction in PCNA, a 1.4 fold increase in type I collage expression, and a 2.1 fold increase in DSPP as compared to wt secretory odontoblasts (Table 1).

Dentin of adult Prnp ${ }^{0 / 0}$ mouse molars had reduced hardness

Microhardness of enamel from sagittally sections of adult mouse molars was not significantly different between $P r n p^{0 / 0}$ and wt mice $(n=6)$ (Fig. 5A). However, the microhardness of both dentin and predentin was significantly lower in $P r n p^{0 / 0}$ mouse molars compared to wtmouse molars $(\mathrm{p}<0.05, \mathrm{n}=6)$ (Fig. 5B,C).

\section{Enamel mineralization in Prnp ${ }^{0 / 0}$ mouse incisors was delayed}

A stereoscopic analysis of ground sagittal sections showed a significantly increased length of the more porous zone in the continuously erupting $\mathrm{Prnp}^{0 / 0}$ mouse incisors $(p<0.05, n=6)$ (Fig. 6E). This zone represents the partially mineralized matrix at the transition stage between the protein-rich secretory stage of enamel and the mineralized maturation stage of enamel. A microCT analysis also showed a significant increase in the length

Fig. 6. Sagittal sections of mandibular incisors showed an increased length of early mineralizing zones in enamel of $\operatorname{Prnp}^{0 / 0}(k o)$ mice by both stereomicrospcopy $(\mathrm{A}, \mathrm{C}, \mathrm{E})$, and microCT (B,D,F). (A) Representative stereomicroscopic image showed the white opaque zone, which occurs when the secretory matrix proteins are removed, leaving an increased porosity zone prior to final mineralization. (B) A representative microCT image taken at the center of a sagittal view of a hemimandible. Length of the porous zone " $X$ ", shown schematically in (C) was significantly increased in the ko incisors as compared to wt incisors (E). Similarly, length of the zone " $Y$ " from the first detectable mineralizing matrix to the point with a relative density $0.94 \mathrm{~g} / \mathrm{cm}^{3}$ of a developing incisor (D) was significantly increased in the ko incisors compared to wt mice (F) ${ }^{*} p<0.05$, $n=6$; Student $t$-test) 
TABLE 1

\section{FOLD DIFFERENCE OF mRNA EXPRESSION IN PRE-ODONTOBLASTS (POB) AND SECRETORY ODONTOBLASTS (SOB) MICRODISSECTED FROM Prnpo/0 (ko) AND wt NEWBORN MOUSE INCISORS}

\begin{tabular}{cccc} 
Fold Difference & PCNA & Type I collagen & DSPP \\
\hline $\mathrm{POB}(k o / w t)$ & $0.88 \pm 0.07$ & $1.85 \pm 0.02$ & $4.17 \pm 0.02$ \\
$\mathrm{SOB}(k o / w t)$ & $0.037 \pm 0.17$ & $1.41 \pm 0.03$ & $2.13 \pm 0.02$ \\
\hline
\end{tabular}

Data are the averages of two independent samples, each measured in triplicate. The standard deviation (indicated by \pm ) for all 6 measurements is included as an indication of reproducibility.

of the early mineralizing (secretory stage) enamel in the Prnpo/0 mouse incisor compared to the wtcontrols ( $\mathrm{p}<0.05, \mathrm{n}=6)$ (Fig. 6F). This analysis was further confirmed by a cross-sectional imaging analysis of the forming mouse incisor enamel (data not shown).

\section{Discussion}

PrP is primarily expressed in the CNS, though modest expression can also be detected in the peripheral nervous system and non-neuronal tissues (Caughey et al., 1988, Li et al., 2001, Manson et al., 1992). Although much is known about the pathologic isoform of PrP, termed PrPsc, the physiological role of normal cellular $\mathrm{PrP}^{\mathrm{C}}$ remains poorly defined (Aguzzi et al., 2008, Chiesa and Harris 2009). The generation of mouse lines devoid of $\operatorname{PrP}$ $\left(P r n p^{0 / 0}\right)$ demonstrated that $\mathrm{PrP}$ is essential for prion propagation (Bueler et al., 1993, Manson et al., 1994b, Prusiner et al., 1993). There were no gross abnormalities initially observed in Prnpo/0 mice, however subsequently, subtle and in some cases disputed phenotypic deficits were reported (Collinge et al., 1994, Lledo et al., 1996). Recent suggestions for $\mathrm{PrP}^{\mathrm{C}}$ function include roles in olfaction (Le Pichon et al., 2009), membrane transport (Fuhrmann et al., 2006), maintenance of peripheral myelin (Bremer et al.), and regulating self-renewal and differentiation status of stem cells (Lee and Baskakov 2010).

Our observations reported in this study are consistent with the previous findings that $\mathrm{PrP}^{\mathrm{C}}$ is localized in human and mouse odontoblasts (Manson et al., 1992, Schneider et al., 2007), as well as secretory ameloblasts in the developing tooth organ (Khan et al., 2010). However, our immunolocalization analysis showed PrPC highly localized in the apical border as well as lateral cell membranes, particularly in secretory odontoblasts and ameloblasts. This location may suggest a potential role of PrP related to crossmembrane transport or signaling transmission.

The tooth organ is a unique system containing neural crest derived mesenchyme and ectoderm derived epithelia that differentiate through reciprocal signaling interactions to form the mineralized dentin and enamel tissues. Dentin, formed by the mesenchymally derived odontoblasts is a collagenous mineralized tissue with many of the similar characteristics as bone. Enamel is the only mineralized epithelial-derived tissue in the human body, and is initially formed as a protein matrix. Enamel matrix proteins immediately attract minerals to initiate mineralization. Enamel proteins are then removed through the actions of proteinases and the overlying ameloblasts, which commit apoptosis as teeth erupt. A hard acellular mineral enamel structure is formed to protect dentin and pulp complex. As described in this study, we used the tooth organ to identify the effects of $\mathrm{PrP}^{\mathrm{C}}$ on epithelially and mesenchymally derived mineralized tissues throughout their differentiation and mineralization.

We used both molars and incisors to investigate the roles of $\operatorname{PrP}^{\mathrm{C}}$ on the different tissues at various stages of tooth formation. Embryonic stage dental mesenchymal cells were compared in vitro for proliferation and differentiation. Dentin formation and mineralization was examined in the unerupted newborn mouse molar, and the fully formed dentin was characterized in erupted mouse molars. Enamel formation was characterized using the continuously erupting incisor where all stages of enamel formation can be identified within a single tooth.

We found stage-specific effects of $\mathrm{PrP}^{\mathrm{C}}$ on tooth organ development. In the dental mesenchyme, when the undifferentiated dental mesenchymal cells lacking PrP were grown in vitro, the cells were highly proliferative compared to the age-matched wtmouse dental mesenchymal cells. When these cells were cultured in a mineralizing media, they formed more mineralizing nodules. This increased nodule formation by Prnp ${ }^{0 / 0}$ embryonic dental mesenchymal cells is likely to be related to their increased proliferation rate, leading to earlier confluence and cell differentiation in vitro.

This observation that rapid dividing dental mesenchymal cells leading to earlier cell differentiation also was evidenced by our observation from the effects of $\mathrm{PrP}^{\mathrm{C}}$ on early dentin, as well as enamel differentiation and matrix maturation in animal model. In newborn mouse molars and incisors lacking of PrP resulted in earlier dentin and enamel matrix formation. This earlier formation of the dentin matrix was also evidenced by increased immunostaining for type 1 collagen and osteopontin, both of which are related to dentin matrix formation and mineralization. Similarly a reduction of decorin in the predentin layer is correlated with dentin maturation (Waddington et al., 2003). qPCR analysis of mRNA isolated from odontoblasts (terminal differentiated dental mesenchymal cells) microdissected by LCM from cryosectioned newborn mouse incisors, showed increased expression of collagen type I, DSPP and reduced PCNA, also consistent with enhanced odontoblast differentiation. Final dentin formation in the Prnpo/0 mice had a reduced microhardness as compared to wt mice, even though dentin mineralization was initiated earlier in tooth formation.

Although there was also earlier mineralization of secretory stage enamel in $P r n p^{0 / 0}$ mice, the length of the secretory and transition stages of the Prnpo/0 mouse enamel formation was longer, with the end result being no difference in final enamel density. This finding that there was no effect of PrP on final enamel mineralization was confirmed by the lack of any change in microhardness of molar enamel.

The varying effects of PrP at different stages of mineralizing tooth tissue formation, point to a common mechanism, potentially related to the altered intracellular calcium regulation. In bone marrow stromal cells, PCNAexpression declines when the intracellular calcium concentration is increased (Ichikawa and Gemba 2009). The similarities between bone marrow stromal cells and dental mesenchymal cells in gene regulation and fate determination (Menicanin et al.), suggest that the increased proliferation rate of undifferentiated Prnp ${ }^{0 / 0}$ dental mesenchymal cells may also relate to PrP modulation of intracellular calcium (Beraldo et al., Kagenishi et al., 2009).

Although the role of calcium in the initiation of tooth tissue cell differentiation is not well defined, the location of PrP at the apical border of both secretory ameloblasts and odontoblasts is consis- 
tent with the hypothesis that this protein is related to $\mathrm{Ca}^{2+}$ transport (Fuhrmann et al., 2006), or regulating $\mathrm{Ca}^{2+}$ homeostasis (Powell et al., 2008).

An interesting application of these studies is the potential to manipulate PrP expression in dental mesenchymal cells, to enhance proliferation in sites of injury. In pulp injury secondary to dental caries or trauma, the dental pulp mesenchymal stem cells must proliferate, and migrate to the area of injury for repairing. Therefore, blocking PrP expression could potentially promote more rapid cell proliferation and pulp healing, including the formation of secondary dentin. The cellular mechanism of PrP regulation of tooth organogenesis and repair will require further studies of the unique processes that promote stage-specific differentiation as the tooth develops.

\section{Materials and Methods}

\section{Tissue samples}

All human tissues were collected under the approval of the University of California San Francisco (UCSF) committee on human research. Developing human tooth organs were obtained from fetal cadaver tissues, obtained through the tissue-sharing program within UCSF.

Wild-type FVB mice were purchased from Charles River Laboratories (Wilmington, MA). PrP knockout mice (Prnpo/0) have been previously described (Bueler et al., 1992), and were on the FVB genetic background. Adult mice were euthanized by $\mathrm{CO}_{2}$ asphyxiation, followed by decapitation, and newborn mice were euthanized by decapitation.

\section{Immunohistochemical localization of PrP in the developing human and mouse incisors}

Maxillas containing tooth organs from 21-24 week-old human fetal tissues, and heads from newborn wt and Prnpo/0 mice, were collected and stored in $20 \%$ sucrose solution for $24 \mathrm{hr}$. The tissues were embedded and frozen in OCT compound (Tissue-Tek, USA), and cryosectioned at a thickness of $12 \mu \mathrm{m}$. The sections were fixed with $95 \%$ methanol and $5 \%$ acetic acid for $20 \mathrm{~min}$ at $-20^{\circ} \mathrm{C}$. Non-specific antibody binding was blocked with $3 \%$ bovine serum albumin for $30 \mathrm{~min}$ at room temperature, followed by washing in PBS with mild shaking for $5 \mathrm{~min}, 3$ times. Slides were incubated with goat anti-PrP antibody (sc-7693, Santa Cruz Biotechnology INC, CA) for $48 \mathrm{hr}$ at $4^{\circ} \mathrm{C}$, followed 3 washes in PBS. The slides were then incubated with secondary antibody (FITC conjugated anti-goat lgG) for $1 \mathrm{~h}$ in the dark at room temperature, washed, and counterstained with $0.5 \mathrm{ug} / \mathrm{mL}$ Hoechst 33324 (Invitrogen, CA) for $5 \mathrm{~min}$. Slides were mounted, observed, and photographed with Nikon Eclipse E800 fluorescent microscope.

The effect of PrPon undifferentiated dental mesenchymal cells in vitro

Pregnant mice were euthanized by standard carbon dioxide asphyxiation at the 18th day of gestation and the mandibular molar tooth buds were microdissected from the embryos under a dissecting microscope (Nikon SMZ 1500) in cold Hank's buffer. The tooth tissues were digested with $2 \mathrm{mg} /$ $\mathrm{ml}$ collagenase/dispase for $2 \mathrm{hr}$ at $37^{\circ} \mathrm{C}$, followed by further digestion with STV (0.05\% trypsin, $0.025 \%$ versene) for $5 \mathrm{~min}$. Pulp dental mesenchymal cells (DMCs) were selectively grown in DMEM H-16 medium supplemented with $10 \%$ fetal bovine serum (Invitrogen, $\mathrm{CA}$ ) and 1\% penicillin-streptomycin at $37^{\circ} \mathrm{C}, 5 \% \mathrm{CO}_{2}$.

To analyze the role of PrP on pulp cell proliferation, DMCs from wt and Prnp ${ }^{0 / 0}$ mice were plated at 5,000 cells/well in a 96-well plate and grown in DMEM, $10 \% \mathrm{FBS}, 1 \% \mathrm{PS}$ at $37^{\circ} \mathrm{C}, 5 \% \mathrm{CO}_{2}$ for 2 days. The cells were then synchronized in serum free DMEM for $24 \mathrm{hr}$ and the media was then replaced with DMEM, 10\% FBS and 1\% PS, $10 \mu \mathrm{l} \mathrm{BrdU}$ and incubated for $24 \mathrm{hr}$. BrdU incorporation was compared using a BrdU chemiluminescence assay (Roche Applied Science, IN), according to the manufacturer's instructions. To determine the effect of PrP on cell differentiation in vitro, DMCs from
E18 Prnp ${ }^{0 / 0}$ and wt mice were grown in mineralization media including DMEM, $10 \%$ FBS, $1 \%$ PS, $10 \mathrm{mM} \beta$-glycerophosphate, $10 \mathrm{nM}$ dexamethasone, and $50 \mu \mathrm{g} / \mathrm{uL}$ ascorbic acid for $2 \mathrm{wks}$. Von Kossa staining was used to identify mineral formation by first washing the cells with PBS, then fixing them in $2 \%$ glutaraldehyde for 15 min, washing, and then incubating the cells in $5 \% \mathrm{AgNO}_{3}$ solution for $30 \mathrm{~min}$ in the dark. The staining was revealed by ultraviolet exposure for $1 \mathrm{hr}$.

\section{Characterization of dentin and enamel matrix formation in Prnp ${ }^{0 / 0}$ and wt teeth}

Mandibles of newborn mice were dissected out under a stereo-microscope, fixed in $10 \%$ neutral-buffered formalin overnight, rinsed with PBS, and dehydrated in a series of graded alcohols. The mandibles were then embedded in paraffin, and serially cross-sectioned at $7 \mu \mathrm{m}$ thickness. Some sections were stained with Masson's trichrome (Hebling et al., 1999), with adjacent sections analyzed following von Kossa staining or immunolocalization of type I collagen, decorin or osteopontin.

For von Kossa staining, sections were dewaxed and incubated in 5\% silver nitrate for $20 \mathrm{~min}$. After washing with distilled water three times, the sections were incubated in 5\% sodium thiosulfate for $2 \mathrm{~min}$, followed by washing in distilled water and then dehydrated in a gradient series of alcohols.

Type I collagen was immunolocalized by first incubating the sections with $1 \mathrm{mg} / \mathrm{ml}$ hyaluronidase for $48 \mathrm{hr}$, rinsing with Walpole's buffer (sodium acetate $1.17 \% \mathrm{w} / \mathrm{v}$, brought to $\mathrm{pH} 4.5$ with glacial acetic acid) followed by PBS, and then incubating with rabbit type I collagen antibody (Chemicon International, CA) overnight at $4^{\circ} \mathrm{C}$. The sections were then rinsed 3 times, incubated $1.5 \mathrm{hr}$ with the peroxidase conjugated secondary anti-rabbit antibody (Dako, Denmark), and visualized with diaminobenzidine substrate (DAB, Sigma, MO).

Decorin, a small leucine-rich proteoglycan (SLRPs) noncollagenous protein, was immunodetected after pretreatment of the sections with chondroitinase ABC (Sigma, $0.25 \mathrm{U} / \mathrm{mL}$ Tris $/ \mathrm{NaCl}$, $\mathrm{pH}$ ) for $20 \mathrm{~min}$ at $37^{\circ} \mathrm{C}$, to activate antigenic sites. After rinsing with PBS, the sections were incubated with rabbit anti-decorin antibody (LF113, generous gifts from Larry Fisher, NIDCR) and detected by DAB as described above. Osteopontin was detected after incubation with anti-OPN antibody (LF123, generous gift from Larry Fisher, NIDCR).

\section{Analyses of gene expression in odontoblasts isolated by microdis- section}

Laser capture microdissection (LCM) was done using a PALM Microlaser system ${ }^{\circledR}$ (Leica). Newborn mouse mandibles ( $w t$ and $k o$ ) were fresh frozen, embedded in OCT, and cryosectioned at $-18^{\circ} \mathrm{C}$ with a thickness of $12 \mu \mathrm{m}$. The sections were mounted on polyethylene naphthalate (PEN) foil glass slides (Leica) with 8 sections per slide. After H\&E staining, the slides were air-dried, and pre-odontoblasts (POB) and secretory odontoblasts (SOB) were separately dissected and catapulted to microtube caps designed for the PALM system. The caps with the collected cells were placed on microtubes containing $50 \mu$ l lysis buffer stock solution (49.3 $\mu \mathrm{L}$ RLT buffer $+0.5 \mu \mathrm{L} \beta-\mathrm{ME}+0.2 \mu \mathrm{L}$ Linear acrylamide), and briefly vortexed upside down. RNA purification was done with RNeasy Plus Micro Kit (Qiagen, $\mathrm{CA}$ ), and reverse transcription was done with Super Script III (Invitrogen, $\mathrm{CA}$ ), following the manufacturer's instructions. Quantitative PCR (qPCR) was done using an Applied Biosystems 7500 (Applied Biosystems Inc., CA) with specific primers to amplify PCNA, type I collagen, and dentin sialophosphoprotein (DSPP) mRNA.

\section{Microhardness of molar enamel and dentin}

Mandibles from 2-month old male mice were embedded in epoxy resin and sagittally ground to the mid-section of the first molars. A flat and highly polished surface was generated using graded series of polishing grit in order to establish orthogonality with the indenter tip (Ho et al., 2004). Microindentation was performed on enamel, dentin (coronally and apically), and predentin (around the pulp chamber and root canal space) under dry conditions using a Knoop diamond indenter (Buehler Ltd., Lake 
Bluff, IL) and a normal load of 10gram force. Each indent was identified using a light microscope and the long diagonal measured using Image-Pro data-acquisition software (Image-Pro Plus Microscope, version 4.0; Media Cybernetics, Silver Spring, MD). Microhardness was determined by: $\mathrm{HK}=$ $0.014229 \mathrm{P} / \mathrm{D}^{2}$ where HK is the Knoop microhardness in gigapascal (GPa), $P$ is the normal load in Newtons (N) and $D$ is the length of long diagonal in millimetres $(\mathrm{mm})$.

\section{Stereomicroscopic and microCT analyses of enamel mineralization}

Mandibles from two-month-old adult male mice were separated into 2 hemimandibles. The left hemimandible from each mouse was embedded in epoxy resin and ground sagittally to the central plane of the incisor using 600 grit silicon carbide paper, photographed under a stereomicroscope, and compared. Enamel formation was characterized by the length of the white opaque enamel zone at the lingual surface of incisors, ending when the more mineralized enamel took on a more translucent color.

Right dry hemimandibles were scanned with a microCT (micro x-ray computed tomography unit; SkyScan $1076 \AA$, Belgium) to characterize the mineral density of the dental tissues in $w t$ and Prnpo/0 mice. Scans were done at $100 \mathrm{kVp}, 100 \mu \mathrm{A}$ with a resolution of $8.87 \mu \mathrm{m}$. 2D sections were stored in a bmp format with indexed gray levels ranging from 0 (black) to 255 (white). DataViewer software (ver 1.4.1 SkyScan) was used to locate a midsagittal plane, which was then used for densitometry $\left(\mathrm{g} / \mathrm{cm}^{2}\right)$ analysis. A cross-sectional plane was taken through the incisor perpendicular to the mesial root of the first molar, and the density of the enamel in the $w t$ and Prnp ${ }^{0 / 0}$ mice was compared.

\section{Acknowledgements}

We wish to thank Mr. Bruno Passet (UMR de Genetique Animale et de Biologie Integrative, INRA, France) for providing mice for histological studies, and Mr. Dominique Le Denmat (EA 2496, University Paris Descartes, France) for his assistance in photographing histological sections. This study was supported by NIDCR grants R21-DE017910 to Pamela Den Besten.

\section{References}

AGUZZI A, BAUMANN F, BREMER J (2008). The prion's elusive reason for being. Annu Rev Neurosci 31: 439-477.

BEI M, MAAS R (1998). FGFs and BMP4 induce both Msx1-independent and Msx1-dependent signaling pathways in early tooth development. Development 125: 4325-4333.

BERALDO FH, ARANTES CP, SANTOS TG, QUEIROZ NG, YOUNG K, RYLETT RJ et al., (2010). Role of alpha7 nicotinic acetylcholine receptor in calcium signaling induced by prion protein interaction with stress-inducible protein 1. J Biol Chem 285: 36542-36550.

BREMER J, BAUMANN F, TIBERI C, WESSIG C, FISCHER H, SCHWARZ P et al., (2010). Axonal prion protein is required for peripheral myelin maintenance. Nat Neurosci 13: 310-318.

BUELER H, FISCHER M, LANG Y, BLUETHMANN H, LIPP HP, DEARMOND SJ et al., (1992). Normal development and behaviour of mice lacking the neuronal cell-surface PrP protein. Nature 356: 577-582.

BUELER H, AGUZZI A, SAILER A, GREINER RA, AUTENRIED P, AGUET $\mathrm{M}$ et al., (1993). Mice devoid of PrP are resistant to scrapie. Cell 73: 1339-1347.

CAUGHEY B, RACE RE, CHESEBRO B (1988). Detection of prion protein mRNA in normal and scrapie-infected tissues and cell lines. J Gen Virol69 (Pt 3): 711-716.

CHIESA R, HARRIS DA (2009). Fishing for prion protein function. PLoS Biol 7: e75.

COLLINGE J, WHITTINGTON MA, SIDLE KC, SMITH CJ, PALMER MS, CLARKE AR et al., (1994). Prion protein is necessary for normal synaptic function. Nature 370: 295-297.

FUHRMANN M, BITTNER T, MITTEREGGER G, HAIDER N, MOOSMANG S, KRETZSCHMAR $\mathrm{H}$ et al. (2006). Loss of the cellular prion protein affects the Ca2+ homeostasis in hippocampal CA1 neurons. J Neurochem 98: 1876-1885.

HARADAH, KETTUNEN P, JUNG HS, MUSTONEN T, WANG YA, THESLEFFI (1999). Localization of putative stem cells in dental epithelium and their association with Notch and FGF signaling. J Cell Biol 147: 105-120.
HEBLING J, GIRO EM, COSTA CA (1999). Human pulp response after an adhesive system application in deep cavities. J Dent 27: 557-564.

HO SP, BALOOCH M, MARSHALL SJ, MARSHALL GW (2004). Local properties of a functionally graded interphase between cementum and dentin. $J$ Biomed Mater Res A 70: 480-489.

ICHIKAWA J, GEMBA H (2009). Cell density-dependent changes in intracellular $\mathrm{Ca} 2+$ mobilization via the $\mathrm{P} 2 \mathrm{Y} 2$ receptor in rat bone marrow stromal cells. J Cell Physiol 219: 372-381.

KAGENISHI T, YOKAWA K, KUSE M, ISOBE M, BOUTEAU F, KAWANO T (2009) Prevention of copper-induced calcium influx and cell death by prion-derived peptide in suspension-cultured tobacco cells. $Z$ Naturforsch C 64: 411-417.

KHAN QE, PRESS CM, SEHIC A, LANDIN MA, RISNES S, OSMUNDSEN H (2010). Expression of prion gene and presence of prion protein during development of mouse molar tooth germ. Eur J Oral Sci 118: 559-565.

LAZARINI F, DESLYS JP, DORMONT D (1991). Regulation of the glial fibrillary acidic protein, beta actin and prion protein mRNAs during brain development in mouse. Brain Res Mol Brain Res 10: 343-346.

LE PICHON CE, VALLEY MT, POLYMENIDOU M, CHESLER AT, SAGDULLAEV BT, AGUZZI A et al., (2009). Olfactory behavior and physiology are disrupted in prion protein knockout mice. Nat Neurosci 12: 60-69.

LEE YJ, BASKAKOV IV (2010). Treatment with normal prion protein delays differentiation and helps to maintain high proliferation activity in human embryonic stem cells. J Neurochem 114: 362-373.

LI R, LIU D, ZANUSSO G, LIU T, FAYEN JD, HUANG JH et al., (2001). The expression and potential function of cellular prion protein in human lymphocytes. Cell Immunol 207: 49-58.

LLEDO PM, TREMBLAY P, DEARMOND SJ, PRUSINER SB, NICOLL RA (1996). Mice deficient for prion protein exhibit normal neuronal excitability and synaptic transmission in the hippocampus. Proc Natl Acad Sci USA 93: 2403-2407.

MANDLER M, NEUBUSERA (2001). FGF signaling is necessary for the specification of the odontogenic mesenchyme. Dev Biol 240: 548-559.

MANSON J, WEST JD, THOMSON V, MCBRIDE P, KAUFMAN MH, HOPE J (1992) The prion protein gene: a role in mouse embryogenesis? Development 115: 117-122.

MANSON JC, CLARKE AR, HOOPER ML, AITCHISON L, MCCONNELL I, HOPE $\mathrm{J}$ (1994a). 129/Ola mice carrying a null mutation in PrP that abolishes mRNA production are developmentally normal. Mol Neurobiol 8: 121-127.

MANSON JC, CLARKE AR, MCBRIDE PA, MCCONNELL I, HOPE J (1994b). PrP gene dosage determines the timing but not the final intensity or distribution of lesions in scrapie pathology. Neurodegeneration 3: 331-340

MCKINLEY MP, HAY B, LINGAPPA VR, LIEBERBURG I, PRUSINER SB (1987) Developmental expression of prion protein gene in brain. Dev Biol 121: 105-110.

MENICANIN D, BARTOLD PM, ZANNETTINO AC, GRONTHOS S. (2010). Identification of a common gene expression signature associated with immature clonal mesenchymal cell populations derived from bone marrow and dental tissues. Stem Cells Dev 19: 1501-1510.

NEUBUSER A, PETERS H, BALLING R, MARTIN GR (1997). Antagonistic interactions between FGF and BMP signaling pathways: a mechanism for positioning the sites of tooth formation. Cell 90: 247-255.

OKADA H, SAKURAI M, YOKOYAMA T, MOHRI S (2010). Disease-Associated Prion Protein in the Dental Tissue of Mice Infected with Scrapie. J Comp Pathol.

POWELLAD, TOESCU EC, COLLINGE J, JEFFERYS JG (2008). Alterations in Ca2+buffering in prion-null mice: association with reduced afterhyperpolarizations in CA1 hippocampal neurons. J Neurosci 28: 3877-3886.

PREMZL M, GAMULIN V (2007). Comparative genomic analysis of prion genes. BMC Genomics 8: 1 .

PRUSINER SB, GROTH D, SERBAN A, KOEHLER R, FOSTER D, TORCHIA M et al., (1993). Ablation of the prion protein (PrP) gene in mice prevents scrapie and facilitates production of anti-PrP antibodies. Proc Natl Acad Sci USA 90 10608-10612.

SCHNEIDER K, KORKMAZ Y, ADDICKS K, LANG H, RAAB WH (2007). Prion protein (PrP) in human teeth: an unprecedented pointer to PrP's function. J Endod 33: 110-113.

SHARPE PT (2001). Neural crest and tooth morphogenesis. Adv Dent Res 15: 4-7. THESLEFF I, NIEMINEN P (1996). Tooth morphogenesis and cell differentiation. Curr Opin Cell Biol 8: 844-850. 
TREMBLAY P, BOUZAMONDO-BERNSTEIN E, HEINRICH C, PRUSINER SB, DEARMOND SJ (2007). Developmental expression of PrP in the post-implantation embryo. Brain Res 1139: 60-67.

VAAHTOKARI A, ABERG T, THESLEFF I (1996). Apoptosis in the developing tooth: association with an embryonic signaling center and suppression by EGF and FGF-4. Development 122: 121-129.

WADDINGTON RJ, HALL RC, EMBERY G, LLOYD DM (2003). Changing profiles of proteoglycans in the transition of predentine to dentine. Matrix Biol 22: 153-161.

\section{Further Related Reading, published previously in the Int. J. Dev. Biol.}

Contribution of mesoderm to the developing dental papilla

Michaela Rothová, Jifan Feng, Paul T. Sharpe, Renata Peterková and Abigail S. Tucker

Int. J. Dev. Biol. (2011) 55: 59-64

Induction of neural crest cells from mouse embryonic stem cells in a serum-free monolayer culture

Yuko Aihara, Yohei Hayashi, Mitsuhi Hirata, Nobutaka Ariki, Shinsuke Shibata, Narihito Nagoshi, Mio Nakanishi, Kiyoshi Ohnuma, Masaki Warashina, Tatsuo Michiue, Hideho Uchiyama, Hideyuki Okano, Makoto Asashima and Miho Kusuda Furue Int. J. Dev. Biol. (2010) 54: 1287-1294

BMP signalling in craniofacial development Xuguang Nie, keijo Luukko and Paivi Kettunen Int. J. Dev. Biol. (2006) 50: 511-521

Study of novel genes involved in odontoblast and ameloblast differentiation FJ Unda, N lehara, S De-Vega, M De-La-Fuente, A Vilaxa, Y Yamada Int. J. Dev. Biol. (2001) 45: 9910-9910

Differential expression of laminin- 5 subunits during incisor and molar development in the mouse K Yoshiba, N Yoshiba, D Aberdam, G Meneguzzi, F Perrin-Schmitt, C Stoetzel, J V Ruch and H Lesot Int. J. Dev. Biol. (2000) 44: 337-340

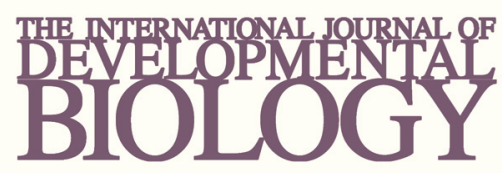

Volume 54 Nos. 6/7

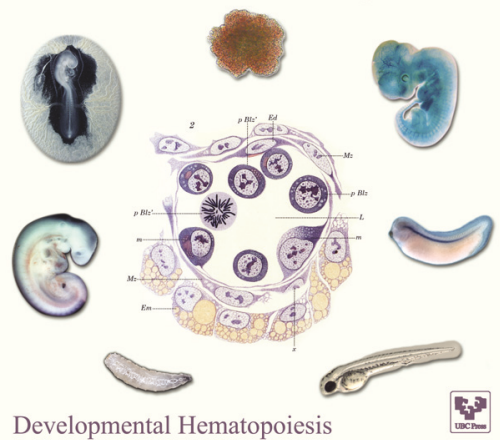

5 yr ISI Impact Factor $(2010)=2.961$

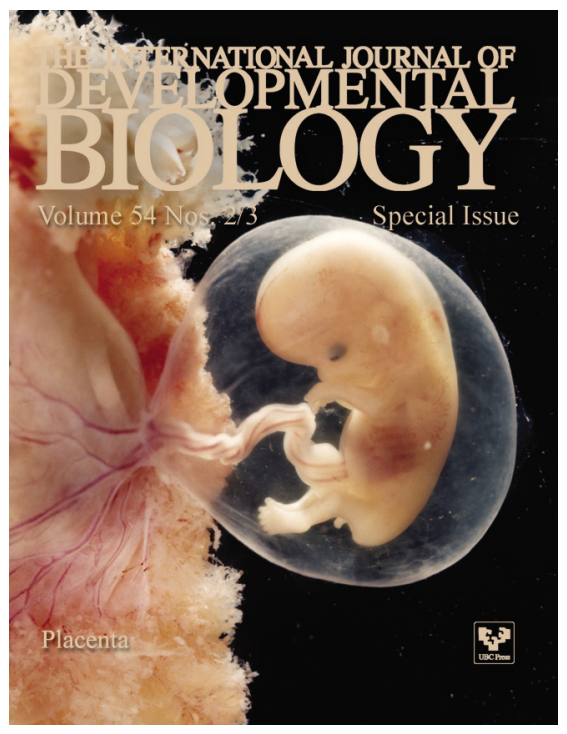

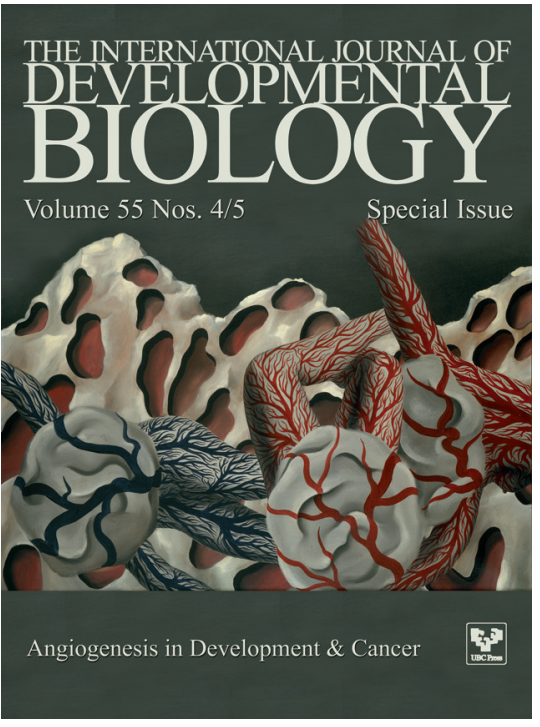

